\title{
Grundtvig e as escolas populares da Dinamarca: interlocuções com Paulo Freire e contribuições à Educação de Jovens e Adultos no Brasil
}

\section{Grundtvig and the Folk High Schools in Denmark: dialogues with Paulo Freire and contributions to Youth and Adult Education in Brazil}

\author{
Maria Clara Di Pierro* \\ Sérgio Haddad**
}

\begin{abstract}
RESUMO
Fruto de pesquisa cujo objetivo foi contribuir para a ampliação de referências teóricas no campo da Educação Popular de Jovens e Adultos no Brasil, o artigo expõe de modo sintético a biografia e as principais ideias pedagógicas do pastor, historiador e filósofo dinamarquês Nicolaj Frederik Severin Grundtvig (1783-1872), cujo pensamento educacional inovador deu origem ao movimento das escolas populares de adultos nos países escandinavos na segunda metade do século XIX. Para situar as obras e o pensamento educacional do autor, e compreender sua influência no surgimento do movimento das escolas populares na Dinamarca, o ensaio descreve o contexto das relações internacionais (conflitos bélicos e redefinição de fronteiras) e de mudanças socioeconômicas e políticas pelas quais o país passou entre os séculos XVIII e XIX, com destaque para a reforma agrária, a emergência social do campesinato e a transição da monarquia absolutista ao regime parlamentar. $\mathrm{O}$ estudo assinala as principais características das escolas populares e aborda brevemente as fases pelas
\end{abstract}

* Universidade de São Paulo. Faculdade de Educação. São Paulo, São Paulo, Brasil. E-mail: mcpierro@usp.br - http://orcid.org/0000-0002-8343-3578

${ }^{* *}$ Ação Educativa. São Paulo, São Paulo, Brasil. E-mail: sergiohaddad@terra.com.br - https:// orcid.org/0000-0002-6243-1813 
quais esse movimento educativo passou até os dias atuais, registrando sua institucionalização nas leis dinamarquesas e nas políticas de educação de adultos do país. Resguardando a singularidade dos contextos históricos e de formação intelectual (que explicam as distintas concepções de povo e de cultura popular), o artigo identifica convergências entre o pensamento do autor dinamarquês e as ideias pedagógicas de Paulo Freire, apoiadas nas respectivas versões do humanismo cristão. Sublinha a similitude das críticas que os autores dirigem à escola tradicional e a ênfase depositada por ambos no diálogo como mediação de uma educação para o esclarecimento e a participação social.

Palavras-chave: Educação de Jovens e Adultos. N. F. S. Grundtvig. Paulo Freire. Escolas populares na Dinamarca

\begin{abstract}
A result of the research whose objective was to contribute to the expansion of theoretical references in the field of Youth and Adult Popular Education in Brazil, this article summarizes the biography and main pedagogical ideas of the Danish pastor, historian and philosopher Nicolaj Frederik Severin Grundtvig (1783-1872), whose innovative educational thinking gave rise to the popular adult school movement in Scandinavian countries in the second half of the 19th century. In order to locate the author's works and educational thinking, and understand his influence on the emergence of the popular school movement in Denmark, the essay describes the context of international relations (war conflicts and redefinition of borders) and the socio-economic and political changes that the country went through between the $18^{\text {th }}$ and $19^{\text {th }}$ centuries, with emphasis on agrarian reform, the social emergence of the peasantry, and the transition from the absolutist monarchy to parliamentary system. The study registers the main characteristics of popular schools and briefly addresses the phases through which this educational movement has passed until the present day, narrating its institutionalization in Danish laws and in the country's adult education policies. Acknowledging the singularity of the historical contexts and intellectual background (which explains the diverse conceptions of people and popular culture), the article identifies convergences connecting the thought of the Danish author and the pedagogical ideas of Paulo Freire, supported in the respective versions of Christian humanism. The study highlights the similarity of the authors' criticism towards the traditional school and their emphasis on dialogue as the mediation of education for enlightenment and social participation.
\end{abstract}

Keywords: Youth and Adult Education. N. F. S. Grundtvig. Paulo Freire. Danish Folk High School 


\section{Introdução}

Referência obrigatória em toda reflexão pertinente ao campo da educação popular, o pensamento de Paulo Freire é o principal aporte teórico da literatura relativa à educação formal e não formal com pessoas jovens, adultas e idosas no Brasil. O reconhecimento da inegável contribuição e relevância das formulações de Freire para esse campo educativo e o da pedagogia crítica não deveria diminuir o interesse por conhecer seus precursores e interlocutores; muito ao contrário, instiga a pesquisar a história e conhecer diferentes correntes de pensamento pedagógico emancipatório que possam enriquecer as análises nesta esfera. $\mathrm{O}$ próprio Freire dedicou-se a isso, estabelecendo numerosos diálogos com Antônio Faundez, Donaldo Macedo, Ira Shor, Henry Giroux, Myles Horton, dentre outros (GADOTTI, 1996, p. 281-282).

A historiadora argentina Adriana Puiggrós (1998) realizou um significativo esforço de mapeamento e interpretação das correntes de pensamento pedagógico que influenciaram a educação popular na América Latina. Seu estudo foi atualizado por Oscar Jara (2020), que procurou formular uma síntese de três décadas de produção de intelectuais vinculados ao Conselho de Educação Popular da América Latina e Caribe (CEAAL), muitos dos quais compõem, ao lado de Freire (ele próprio cofundador e um dos presidentes de honra do Conselho), as principais referências da comunidade científica brasileira quando o tema é a educação popular de jovens e adultos.

Outros vetores de abertura para a América Latina do pensamento pedagógico brasileiro sobre a educação popular de adultos foram o escritório regional da UNESCO, no Chile, e as redes nucleadas pelo Centro de Cooperação Regional para a Educação de Adultos na América Latina e o Caribe (sediado no México) e pelo Instituto Paulo Freire, aos quais vincularam-se intelectuais como José Rivero, Graciela Messina, Carlos Alberto Torres, Rosa Maria Torres, Sylvia Schmelkes, Pablo Latapi, dentre outros.

Contudo, salvo os divulgadores da educação permanente cujas obras foram difundidas pela Organização das Nações Unidas para a Educação, a Ciência e a Cultura (UNESCO), tais como Jacques Delors, Edgar Faure ou Ettore Gelpi, e alguns intelectuais como Rui Canário, Licínio Lima, Ramón Flecha e Trintan McCowan, os diálogos com autores de outras línguas e regiões do mundo são ainda raros na produção brasileira sobre as pedagogias emancipatórias na formação de jovens e adultos. 
Quando o Programa Europeu de Educação de Adultos recebeu o nome de Grundtvig ${ }^{1}$, em homenagem ao educador dinamarquês praticamente desconhecido no Brasil, fomos instados a saber mais sobre esse autor, sobre as escolas populares dinamarquesas inspiradas em seu pensamento, e sobre sua influência na educação de pessoas adultas na Europa e em outros continentes. Esse interesse foi aguçado pelo fato de que, ao difundir-se internacionalmente, as ideias pedagógicas de Grundtvig têm sido consideradas convergentes àquelas de Paulo Freire (BHATTACHARYA, 2010; WARREN, 2011), o que nos levou à elaboração de um projeto de pesquisa a esse respeito ${ }^{2}$.

A investigação sobre Grundtvig não pretendeu a importação de modelos europeus, mas visou ampliar as referências teóricas para pensar a educação popular de adultos mediante a apropriação crítica de um autor até então desconhecido no Brasil. O presente artigo torna públicos alguns dos resultados da pesquisa, sintetizando a biografia e as principais ideias pedagógicas de Grundtvig, delineando o histórico das escolas populares da Dinamarca, indicando, ao final, algumas similitudes com pensamento freiriano.

\section{Primeiras aproximações ao pensamento grundtviguiano}

Em 2014, por ocasião do Seminário Educação Popular Hoje, organizado pela Ação Educativa em São Paulo, a pesquisadora italiana Marcella Milana, que então era professora na Universidade de Aarhus (Dinamarca), proferiu palestra sobre a experiência de educação popular na Escandinávia ${ }^{3}$. Segundo ela, o diferencial da educação de jovens e adultos nos países nórdicos (que ainda hoje exerce grande influência internacional) reside nas escolas populares

1 O Programa Grundtvig sobre Educação de Adultos compôs o Programa Educação ao Longo da Vida (ELV) da Comunidade Europeia e distribuiu $€ 358$ milhões para projetos multilaterais entre 2007 e 2013. Posteriormente foi absorvido pelo Programa Erasmus + 2014-2020 (European Region Action Scheme for the Mobility of University Students).

2 Coordenada pelo Dr. Sérgio Haddad (UCS) e desenvolvida no período 2016-2020, a pesquisa foi apoiada pelo CNPq e pela FAPESP. A equipe foi formada também pelos colaboradores Drs. Angélica Kuhn (Universidade Cruzeiro do Sul), Maria Clara Di Pierro (Faculdade de Educação da Universidade de São Paulo) e Roberto Catelli Jr. (Ação Educativa), assistidos pelas estudantes Beatriz Ribeiro, Gabriela Zepponne, Janaina Uemura e Vitória Luiza Fábio.

$3 \mathrm{O}$ vídeo da palestra pode ser consultado em: https://www.youtube.com/watch?v=jwUbf4lGbw. 
públicas, ou Folke Hojskoler ${ }^{4}$, como são denominados em dinamarquês esses centros de educação não formal destinados a maiores de 17 ou 18 anos de idade, que, sob gestão democrática e currículos abertos, sem compromissos com avaliações ou certificação, promovem uma diversidade de estudos e práticas culturais, esportivas e cívicas para o esclarecimento dos cidadãos e sua participação na vida democrática por meio do diálogo, contato com a natureza, vivência artística e comunitária prolongada. Nos dias atuais, são cerca de uma centena de escolas mantidas por associações civis e cofinanciadas pelo Estado, que promovem cursos aos quais acorrem voluntariamente tanto jovens que concluíram a educação média e ainda não acessaram o ensino superior, quanto adultos, inclusive imigrantes e desempregados, que podem nelas residir ou frequentar diariamente ${ }^{5}$. Naquela palestra, Milana mencionou que a origem dessa experiência remonta ao movimento de educação popular que se difundiu na Dinamarca na segunda metade do século XIX, fortemente influenciado pelo pensamento pedagógico do pastor luterano, historiador e poeta Nicolaj Frederik Severin Grundtvig (1783-1872).

Em busca de mais informações sobre este pensador, encontramos na literatura brasileira apenas duas referências muito breves. Em monografia de 1938, o educador fluminense Paschoal Lemme (1905-1997), ao criticar a pouca atenção dedicada à educação dos adultos e sua abordagem restrita ao campo escolar, fez a seguinte ressalva:

Salvo na Dinamarca, onde se assinala um interessantíssimo movimento de escolas populares para adultos, que se reveste de características peculiares, relacionado com a própria formação da nacionalidade e inspirado pela ação verdadeiramente profética de Grundtvig, não se percebe, compulsando a história das instituições de educação, vigor notável, preocupação absorvente com o problema, a não ser em casos isolados (LEMME, 2010, p. 129).

Outra breve referência a N. F. S. Grundtvig foi encontrada no livro em que Paulo Freire dialoga com o educador norte-americano Myles Horton

4 Nos textos em inglês, a expressão dinamarquesa Folke Hojskoler tem sido traduzida como Folk High School, o que pode associar tais escolas a um grau de ensino do sistema escolar formal (secundário ou superior), o que não corresponde à sua natureza de escola livre que promove educação não formal, motivo pelo qual optamos neste artigo por traduzir a expressão simplesmente por escolas populares.

5 Para uma compreensão mais aprofundada sobre essas escolas, consultar os estudos de caso de Milana e Sorensen (2020) e de Haddad et al. (2020). 
(1905-1990), um dos cofundadores, em 1932, da Highlander Folk School do Tennessee, inspirada nas escolas populares dinamarquesas, que contribuiu para a formação de lideranças dos movimentos pelos direitos civis nos Estados Unidos da América (EUA). Em um momento da conversação, Freire menciona uma palestra proferida por Horton, em um workshop realizado na Dinamarca sobre o autor, e publicada em 1983 na obra "Grundtvig's ideas in North America: influences and parallels". O diálogo não deixa claro se Freire esteve presente ao evento mencionado ou se leu o trabalho posteriormente (FREIRE; HORTON, 2011, p. 50). De todo modo, encontramos aí evidência de que Paulo Freire conhecia o autor dinamarquês e a experiência das escolas populares dos países escandinavos, o que já era esperado, em se tratando de um estudioso que por anos viveu na Suíça trabalhando no Conselho Mundial de Igrejas e viajando ao redor do globo para assessorar programas de educação de adultos. Contudo, o autor dinamarquês não foi encontrado por nós citado nas obras de Freire.

Além dessas breves menções a Grundtvig por autores brasileiros, encontramos em língua portuguesa apenas uma dissertação de mestrado defendida na Universidade de Lisboa (Portugal), de autoria de Gato (2011), que apresenta a biografia e ideias pedagógicas do autor dinamarquês, bem como as escolas populares daquele país, relatando observações realizadas no International People's College, em Elsinore.

A quase totalidade da bibliografia de e sobre Grundtvig que apuramos com a pesquisa encontra-se em dinamarquês ou inglês, tendo a investigação se baseado principalmente nas antologias traduzidas para a língua inglesa dos textos sobre educação do autor (BROADBRIDGE; WARREN; JONAS, 2011; JENSEN, 1984; KNUDSEN, 1976; LAWSON, 1991) ou de seus estudiosos e comentadores $^{6}$.

\section{O contexto geopolítico e sócio-histórico da Dinamarca do séc. XIX}

Localizado no extremo norte da Europa, o território que hoje corresponde à Dinamarca é formado pela península da Jutlândia e um arquipélago no mar Báltico, posição que permite o estratégico controle do acesso à navegação com o Mar do Norte.

6 Um dos produtos da pesquisa é um repositório de textos de e sobre N. F. S. Grundtvig, disponibilizado na Biblioteca Digital da Ação Educativa em: http://www.bdae.org.br/. 
Habitada desde a pré-história, a Escandinávia é conhecida como território de origem dos Vikings, que exerceram domínio comercial e marítimo no norte da Europa entre os séculos VIII e XI, e cuja mitologia ${ }^{7}$ foi ressignificada pelo nacionalismo romântico no século XIX.

O território foi cristianizado entre os séculos VIII e X e, após a Reforma, o protestantismo se difundiu, tornando-se hegemônico no séc. XVI, quando as terras da Igreja Católica foram confiscadas pelo Estado. Na atualidade, 78\% da população (que soma 5,8 milhões de pessoas) pertence à Igreja Evangélica Luterana da Dinamarca, considerada religião oficial do Reino desde a Constituição de 1849.

Suécia, Noruega e Dinamarca possuem profundos laços históricos e culturais, constituindo-se como monarquias absolutas em período relativamente tardio, quando comparado a outras nações europeias. No século XIV, a União de Kalmar reuniu diferentes reinos situados nas terras que hoje correspondem aos países escandinavos sob um único monarca. Em 1523 a Suécia se separou dessa União. A Noruega esteve sob o domínio da Dinamarca até 1814, quando esta, derrotada nas guerras napoleônicas, teve que cedê-la à Suécia, situação que vigorou até 1905. Suécia e Dinamarca disputaram ao longo dos séculos XVIII e XIX territórios, autonomia e controle da navegação no Báltico, motivo também da ocupação inglesa no início do séc. XIX, o que inviabilizou que a Dinamarca mantivesse a neutralidade nas guerras napoleônicas (o que até então fora chave para o êxito de seu comércio marítimo).

Confrontos bélicos também envolveram o domínio sobre os ducados de Schleswig e Holstein, vinculados ao território dinamarquês, cujo Reino foi derrotado nas sucessivas disputas com a Confederação Germânica, a Prússia e a Áustria entre 1848 e 1851, e depois em 1864. O norte de Schleswig retornou à jurisdição dinamarquesa somente em 1920, por decisão plebiscitária após a derrota da Alemanha na $1^{\mathrm{a}}$ Guerra Mundial; o restante da região compõe Schleswig-Holstein, o estado mais setentrional da atual federação alemã.

Esse contexto de formação do Estado nacional moderno e de disputas territoriais é explicativo de alguns aspectos do pensamento educacional de Grundtvig, como seu viés nacionalista e a ênfase na valorização da língua materna, da história e mitologia ancestral na conformação da identidade do povo dinamarquês.

Desde o final do século XVIII e ao longo do século XIX, o Reino da Dinamarca sofreu profundas transformações socioeconômicas, geopolíticas

7 Narrativas orais de lendas pré-cristãs dos povos nórdicos, em especial dos Vikings, preservadas nas eddas islandesas (coletâneas de textos em verso e prosa datadas do séc. XIII que recompilam fragmentos daquelas narrativas). 
e culturais, a começar pela abolição, em 1788, da legislação que submetia os camponeses à condição de vassalos da aristocracia proprietária de terras. A reforma agrária dinamarquesa, que se estendeu até 1807, é considerada particularmente bem sucedida, pois proporcionou a democratização do acesso à terra e elevação da produtividade do campo, sustentadas na promoção do cooperativismo e na provisão de crédito agrícola, assistência técnica e inovação, informação e educação (que se tornaria obrigatória em 1814 ) ${ }^{8}$, em um contexto de prosperidade comercial e expansão demográfica (ABRAMOVAY, 2007; BAACK, 1977). O sucesso da reforma agrária explica a emergência do campesinato - agora conformado por pequenos proprietários rurais - como classe emancipada na sociedade dinamarquesa do séc. XIX, cuja participação esclarecida na vida política Grundtvig iria reivindicar e promover por meio da educação popular.

Diferentemente de outras nações europeias que foram conflagradas pelos movimentos políticos revolucionários que varreram o continente em 1848, a Dinamarca realizou um trânsito relativamente pacífico do absolutismo esclarecido à monarquia constitucional, graças à aliança entre os pequenos proprietários rurais e setores da pequena burguesia urbana (comerciantes, funcionários públicos, professores universitários). Em 1831, no reinado de Frederick VI, foram convocados os primeiros conselhos consultivos, em que o povo foi convidado a participar das decisões políticas da nação. O sucessor, Christian VIII, retrocedeu nas medidas liberalizantes, mas teve que ceder às reivindicações populares quando, em 1848, Copenhague foi tomada por uma manifestação de cerca de 15 mil dinamarqueses. Em 1849 foi promulgada a Constituição liberal, que consolidou o novo regime monárquico parlamentarista.

A relativa prosperidade econômica e a modernização social e política foram acompanhadas, ao longo do séc. XIX, por um florescimento cultural que ficou conhecido como "a era de ouro da Dinamarca", de que foram expoentes o escritor Hans Christian Andersen (1805-1875), o filósofo Soren Kierkgaard (1813-1855), o compositor Edvard Grieg (1846-1907) e o pastor, historiador, poeta e filósofo Nikolaj Frederik Severin Grundtvig (1783-1872), menos conhecido no exterior que seus contemporâneos.

8 A Dinamarca foi o segundo país do mundo (após a Prússia) a introduzir na legislação a escolaridade obrigatória para todas as crianças entre os 7 e os 14 anos. 


\section{Notas biográficas sobre Grundtvig}

N. F. S. Grundtvig teve vida longa: nasceu em 1783 e faleceu em 1872 aos 89 anos. Sendo o mais novo dentre os filhos de um pastor luterano pietista e conservador, foi criado para seguir os passos do pai. Aprendeu a ler cedo, desenvolvendo grande apreço pela leitura já na infância, estimulado pela família que vivia no sul da Zelândia (a maior das ilhas do arquipélago dinamarquês). Aos nove anos foi enviado a um preceptor e em 1798 mudou-se para Aarhus, na Jutlândia, para realizar os estudos secundários. Entre 1800 e 1803 cursou Teologia na Universidade de Copenhague. Foi educado na tradição iluminista europeia, mas foi influenciado também pelo romantismo alemão e pela mitologia nórdica.

Desgostoso das experiências acadêmicas em Aarhus e Copenhague, desenvolveu uma perspectiva crítica ao ensino livresco, descolado da experiência de vida dos estudantes e da cultura nacional, realizado em latim e centrado na memorização e nos exames, que ele designou como escolas da morte, às quais viria a contrapor uma escola para a vida, enraizada na cultura popular, e caracterizada pela interação oral viva na língua materna.

Sua vida privada foi marcada por três casamentos $(1818,1851$ e 1858) e episódios de desequilíbrio psíquico associados a frustrações amorosas ou conflitos no âmbito da Igreja.

No campo eclesial, contestou aspectos da religião penitencial luterana e pregou um cristianismo voltado à humanização no espaço secular, posição que the rendeu censura e restringiu sua atuação como pastor. Teve breves passagens como pároco até que, aos 55 anos, foi designado capelão de Vartov a um asilo de idosos em Copenhague, onde pregou até o final da vida.

Sua extensa e diversificada obra compreendeu poesias e ensaios (sobre teologia, filosofia, história e educação), hinos e salmos. Com patrocínio da Coroa, dedicou-se a recuperar a herança cultural dinamarquesa, compilando e traduzindo narrativas históricas e mitos nórdicos. Em 1808 publicou Mitologia Nórdica, cuja segunda edição, de 1832, continha um preâmbulo que introduzia suas ideias sobre educação.

Durante suas pesquisas, realizou viagens de estudos à Inglaterra em 1829, 1830 e 1831, quando entrou em contato com o arejado ambiente acadêmico dos colleges de Oxford e Cambridge, e com o novo sistema de representação parlamentar daquele país, o que influenciou seu pensamento pedagógico e político.

No retorno à Dinamarca, tomou parte das primeiras Assembleias Populares em Roskilde (então capital) entre 1835 e 1836, e mais tarde foi membro do 
Parlamento de 1848 a 1858, participando da elaboração da Constituição liberal de 1949.

Datam das décadas de 1830 e de 1840 seus escritos que tratam de educação, sempre relacionada à construção da nação dinamarquesa e de um sistema político representativo de seu povo. A primeira dessas obras, "O trevo de quatro folhas dinamarquês", de 1836, foi motivada pela inédita escuta à população nas primeiras assembleias populares consultivas daquela década. As folhas do trevo seriam o reino, o povo, a pátria e a língua materna, e a chave para fortalecer a voz popular, fundamentalmente camponesa, nas assembleias, seria a criação de uma escola para jovens e adultos centrada nesses elementos da cultura comum, com a mediação da poesia e das lendas escandinavas preservadas pela tradição oral.

A pedido do Rei Christian VIII, Grundtvig sistematizou suas propostas educacionais em Escola para a vida, de 1838, em que prosseguiu sua crítica ao ensino em latim, centrado nos livros e exames, contrapropondo a aprendizagem pela interação social viva e a educação mútua comunitária e residencial em escolas populares.

Em 1840 publicou "Pleito por uma ideia de Escola Popular Dinamarquesa em Søro", e em 1847 "Congratulações à Dinamarca pela escola dinamarquesa de adultos" 10 , obras em que argumentou em favor das escolas populares e detalhou sua proposta de ensino mútuo e dialógico, e de gestão escolar por conselhos deliberativos. O centro do argumento é que as pessoas comuns deveriam participar da vida cívica por meio das assembleias populares, o que requeria formação para a autonomia proporcionada pelas escolas populares, onde vivenciariam a eleição e participação em conselhos consultivos assessores da administração escolar.

Em outras obras, Grundtvig também advogou em favor de um universidade pan-nórdica, voltada ao desenvolvimento científico e humanístico, convocando os principais cientistas e pensadores nórdicos para esta tarefa.

9 Por muitos anos, Grundtvig advogou sem sucesso pela transformação da Academia de Søro em uma escola popular. Trata-se de um edifício histórico, construído originalmente como monastério no séc. XII, confiscado pelo Estado na Reforma Protestante e transformado em instituição educativa que, ao longo da história, cumpriu fins diversos, dentre os quais o de academia militar. Foi reconstruída em 1750, após um incêndio, e remodelada na década de 1820, sendo reaberta em 1825 , porém com caráter diverso do pretendido por Grundtvig.

10 Nesse texto, Grundtvig saúda a criação de escolas populares para adultos, mas reafirma suas críticas ao ensino tradicional, ao qual autoridades e acadêmicos estariam teimosamente apegados. O título original, vertido ao inglês por Knudsen (1976) como "Congratulations to Denmark on the Danish Blockhead and the Danish High School", contém uma ironia para a qual não encontramos tradução apropriada, motivo pelo qual suprimimos do título em português a adjetivação empregada pelo autor. 
Embora suas ideias tenham inspirado o movimento das Folke Højskole, Grundtvig não participou diretamente da criação e implementação das escolas populares dinamarquesas que colocaram em prática sua filosofia educacional, tarefa assumida por seguidores como Christen Kold e Christian Flor.

\section{Uma aproximação às ideias pedagógicas de Grundtvig}

Como outros filósofos do seu tempo, Grundtvig interessou-se por repensar o papel da educação em sociedades que transitavam da autoridade das igrejas e monarcas para a soberania popular, requerendo a formação de indivíduos livres, autônomos e dotados de iniciativa. Depreende-se dos textos do pensador dinamarquês uma concepção que atribui à educação o sentido de despertar e promover o esclarecimento ${ }^{11}$ do indivíduo para a vida, entendido como o processo de construção da identidade pessoal e espiritual do sujeito, que se realiza no interior de uma tradição, cultura e sociedade, proporcionando um senso de pertença a uma comunidade nacional e, dessa forma, estimulando sua participação na esfera pública.

Uma educação assim compreendida não poderia, segundo Grundtvig, ser desenvolvida em instituições elitistas tais como as escolas secundárias e superiores existentes na Dinamarca à época - que ele qualificou de escolas da morte ou da escuridão - onde se difundia a cultura germânica da aristocracia mediante o ensino em latim e a aprendizagem pela memorização dos livros. Ele qualificou tal educação como retrógrada, anticientífica, excludente e contraproducente quando se quer formar a juventude e os adultos para a participação cidadã, e criticou seu divórcio com as tradições culturais do povo dinamarquês, marcadas pela força da comunicação oral na língua materna.

Visando à construção de uma escola partilhada por jovens e adultos dinamarqueses de todos os extratos sociais, a filosofia educacional de Grundtvig propôs deslocar a centralidade dos livros em favor da interação viva ${ }^{12}$, substituir o monólogo do professor pelo diálogo e companheirismo entre educadores e

11 Grundtvig utiliza o termo dinamarquês oplysning, que tem sido traduzido para o inglês por enlightenment, usualmente vertido para o português como esclarecimento.

12 Nas versões de suas obras em inglês, essa noção é traduzida por living word, ou palavra viva, conceito que encontra paralelo também no pensamento teológico do autor, que contrasta o contato frio com a leitura do texto bíblico à vivacidade da pregação oral entre os membros da comunidade de fé. 
educandos, valorizando a oralidade, o canto entoado no coletivo e as narrativas histórico-poéticas dos povos nórdicos ancestrais, concebidas como formas de encontro entre as pessoas em corpo e espírito.

Entusiasmado com a potência das assembleias populares para dar voz aos camponeses até então alijados da vida política da nação, Grundtvig aspirava uma educação que preparasse para a participação na esfera pública. Seu júbilo fica evidente em carta escrita ao empresário Gunni Busck, datada de 1836:

Fui atingido ultimamente pela ideia de que o sentimento nacional dinamarquês original e a voz do povo, vitalizando tudo aquilo que é dinamarquês, a voz que estive procurando em livros velhos e dentro de mim mesmo - eles de fato ressurgiram dos mortos na Assembleia Popular (GRUNDTVIG, 1836 apud LAWSON, 1991, p. 19)

Para promover esse tipo de educação, advogou em favor da criação de escolas populares, sem exames de acesso ou creditação, voltadas à formação integral de jovens e adultos ${ }^{13}$ de origens sociais diversas.

[...] uma escola popular para nossa juventude de homens do povo, por meio do qual a educação e o que desejamos ver tanto nas Assembleias Populares como no seu eleitorado serão cuidadosamente fornecidos (GRUNDTVIG, 1836 apud LAWSON, 1991, p. 35)

Propôs também que tais escolas fossem geridas democraticamente por conselhos participativos, e que educadores e educandos pudessem nelas residir por um período relativamente prolongado e conviver em comunhão e diálogo franco, compartilhando também trabalhos manuais, culturais, viagens, atividades esportivas e ao ar livre.

Grundtvig se opunha a que tais escolas emitissem certificados ou realizassem exames (aos quais se referiu ironicamente como negócio da China) privilegiando o interesse e motivação intrínsecos de educandos e educadores em realizar aprendizagens significativas para suas vidas. Conforme Rui Pedro

13 Embora sua filosofia também se aplicasse à educação das crianças, Grundtvig centrou esforços na educação dos jovens e dos adultos porque estes possuiriam energia e desejo pela vida, e já teriam experiências para compartilhar. 
Madeira Gato (2011, p. 29) que cita Grundtvig ([1840] apud LAWSON 1983, p. 64):

O que é adquirido unicamente com o propósito de passar no exame é naturalmente depressa esquecido após ultrapassado o exame. Tal acontece tanto sem causar qualquer tipo de problema de consciência, como sem provocar qualquer tipo de esclarecimento ou prazer, mas escurece e amarga a vida. O que é adquirido apenas porque é desejado, nunca é esquecido [...].

Exceção feita à sua insistência no emprego das narrativas poético-históricas da cultura dinamarquesa na língua materna, Grundtvig pouco se dedicou a especificar currículos padronizados, preferindo atribuir autonomia para que cada escola selecionasse os conteúdos de aprendizagem em conformidade com as expectativas e interesses dos estudantes e professores.

Os professores necessários a esse projeto educativo deveriam ser selecionados menos por títulos acadêmicos e mais pela experiência e pelo perfil, que valorizava a capacidade de cuidar e a liderança fundada no entusiasmo, companheirismo, abertura ao diálogo e à convivência democrática.

Embora fosse pastor e homem de fé, Grundtvig admitiu a liberdade de religião e defendeu que as escolas deveriam abdicar de questões religiosas, que seriam exclusivas das esferas das famílias e da Igreja.

\section{O movimento dinamarquês das escolas populares de jovens e adultos}

O pleito de Grundtvig perante o Rei para que a Academia de Søro fosse convertida em uma Folke Højskole não foi bem sucedido ${ }^{14}$, e ele próprio não criou escolas, mas suas propostas foram colocadas em prática por seguidores. Dentre esses adeptos, a literatura confere destaque aos pioneiros Christian Flor (1792-1875) e Christen M. Kold (1816-1870), que compartilhavam com Grundtvig a fé cristã e a convicção no esclarecimento por meio da palavra

14 O Rei Christian VIII faleceu logo após aquiescer com a proposta de Grundtvig em fins de 1857 , e o governo seguinte não deu continuidade ao projeto. 
viva, do diálogo e das narrativas orais na língua materna em que se enraíza a identidade nacional dinamarquesa.

A primeira escola popular foi estabelecida em Rødding, no sul da Dinamarca, em 1844, sob a liderança do pastor Christian Flor. Quando em 1864 a região de Schleswig foi invadida pela Prússia, a escola teve que se mudar para Askov, ao norte da nova fronteira, e representou um polo de resistência à imposição da língua e cultura alemãs na região. Os historiadores da educação dinamarquesa concordam que, a exemplo do que ocorreu em Schleswig, a emergência do sentimento nacional provocada pela perda de territórios para a Suécia e a Prússia concorreu para a ampliação do movimento das escolas populares.

A difusão das escolas populares deve-se também à insatisfação com os conteúdos e métodos tradicionais adotados nas escolas infanto-juvenis, cuja frequência se tornara obrigatória desde 1814. Essa contrariedade conduziu, em 1855, à promulgação da nova lei sobre o ensino primário, que reconheceu o direito dos pais à escolha do tipo de instrução dos filhos (admitindo inclusive o ensino domiciliar), o que ampliou a autonomia pedagógica dos professores e o espaço para as escolas populares. Antes disso, porém, em 1851, o parlamento já aprovara a primeira normativa facultando o apoio financeiro governamental às escolas populares, que não tiveram sua liberdade curricular e pedagógica afetada por essa institucionalização graças à aceitação das ideias de Grundtvig e do sucesso das escolas criadas por Christian Flor e outros pioneiros.

Impossibilitado de trabalhar nas escolas públicas por suas ideias pedagógicas pouco convencionais, o professor Christen Kold usou recursos próprios, doações de apoiadores e uma bolsa do Estado para criar, em fins de 1851, em Ryslinge, uma escola gratuita nos moldes propostos por Grundtvig, onde compartilhou o ensino com o amigo Anders Christian Poulsen Dal. A escola recebia rapazes de 15 a $20 \operatorname{anos}^{15}$ e funcionava de novembro a março, pois no restante do ano os jovens precisavam retornar ao trabalho no campo.

[...] Kold e Poulsen Dal viviam nas mesmas condições dos estudantes, comiam a mesma comida e dormiam ao lado deles no loft acima da sala de aula. Uns dez anos depois, um visitante sueco à escola popular de Kold em Dalum descreveu o homem e seu ensino da seguinte maneira: $[. .$.

15 As primeiras escolas eram frequentadas apenas por pessoas do sexo masculino, mas a partir de 1861 elas foram abertas também às mulheres e moças, em períodos distintos daqueles em que a escola recebia os rapazes. A mulheres, contudo, só conquistariam o direito de voto na Dinamarca em 1915. 
com a exceção da forte presença exercida pela personalidade de Kold, não há nada na escola que a faça diferente de outras escolas grundtviguianas ou das escolas populares em geral. Há os mesmos métodos de ensino descontraídos, a mesma ausência de lições compulsórias, autoinstrução por meio da leitura de autores admiráveis, escrita de dissertações e, finalmente, canções agradáveis e vigorosas (BJERG, 1994, p. 25).

Em 1862 Kold fundou uma nova escola em Dalum, que no ano seguinte passaria também a receber moças nos meses de verão.

Outras escolas populares haviam sido criadas antes daquelas inauguradas por Kold: Uldum (1849), Hindholm (1852) e Viby (1857), muito diversas entre si. A partir da década de 1860, houve uma verdadeira explosão de escolas populares: Vallekilde (1865) e Rodkilde (1866) são algumas das 55 escolas que em 1875 chegaram a acolher quatro mil estudantes, estimando-se que $15 \%$ da juventude rural as tenha frequentado naquele período. Elas se tornaram também centros culturais das comunidades, sediando encontros de agricultores para aprendizado, canto coral e entretenimento. O reconhecimento da relevância desse movimento fez com que em 1892 a legislação regulamentasse o subsídio público às escolas populares, assegurando sua liberdade pedagógica.

O apoio financeiro definido em 1892 era composto por um montante fixo por escola, um montante por estudante inscrito, cobertura de até um terço das despesas com salários e formação do pessoal e uma bolsa especial para os estudantes oriundos de famílias pobres (GATO, 2011, p. 42).

O movimento se estendeu a toda a Escandinávia, onde as primeiras escolas populares foram fundadas em1864 na Noruega, em 1868 na Suécia, e em 1889 na Finlândia. Em 1918, ao final da I Guerra, já era 68 o número de escolas populares, que se difundiram também para a Holanda e Alemanha. Imigrantes dinamarqueses levaram a experiência das escolas populares ao Canadá e aos Estados Unidos para cultivar a língua e as tradições ${ }^{16}$.

No transcorrer do séc. XX, a proposta pedagógica das escolas populares sofreu ajustes às novas condições históricas e socioeconômicas. Até a década de

16 Mais tarde, uma segunda geração de escolas populares foi fundada nos EUA por ativistas dos direitos civis que conheceram o movimento escandinavo e recriaram a proposta em seu contexto. É o caso de Myles Horton, fundador, em 1932, da Escola Popular Highlander no Tennessee, conforme mencionado anteriormente. 
1940 elas cumpriram a função original de promover a formação da população rural $^{17}$, embora em determinados contextos tenham sido criados cursos de duração mais breve para atrair também jovens e adultos dos meios urbanos.

Em 1940 a Dinamarca foi ocupada pela Alemanha nazista, mas dirigentes e população não colaboraram com as forças de ocupação; o país não sofreu grandes perdas humanas e materiais, mas a economia, dependente das relações comerciais com a Inglaterra, foi duramente afetada. Em 1942 uma nova lei regulando o financiamento público das escolas populares foi aprovada visando engajá-las no esforço de qualificação profissional da força de trabalho.

A reconstrução econômica do pós-guerras modernizou a economia agrícola, promovendo a urbanização e industrialização; a educação escolar obrigatória foi ampliada e universalizada, e a oferta de educação profissional se diversificou. Nesse novo contexto as escolas populares (que à época somavam 54) enfrentaram dificuldades de mobilizar seu público original - a população rural - e justificar sua relevância social.

Foi no momento imediatamente posterior à $2^{\mathrm{a}}$ Guerra Mundial que o ideal histórico-poético de Grundtvig para as escolas populares foi revisto pelo teólogo e historiador da igreja Hal Koch (1904-1963), que sublinhou a dimensão política da educação, colocando ênfase na promoção dos direitos humanos e dos valores democráticos, perspectiva esta que concretizou na escola de Krogerup, fundada em 1946 por ele e outros educadores, e que foi referência para as demais escolas populares nas décadas seguintes.

Os movimentos e transformações socioculturais da década de 1960, em particular o movimento juvenil, redefiniram o sentido e trouxeram para as escolas populares um novo público, formado por jovens urbanos com escolarização secundária completa, que aspiravam espaços em que pudessem se expressar com liberdade em processos de formação com finalidades outras que não a preparação para o trabalho. As práticas artísticas ganharam relevo e os controles de comportamento até então vigentes (como a restrição ao uso de bebidas alcóolicas ou de frequência a dormitórios segregados por sexo) passaram a ser contestadas nas instâncias de gestão democrática. Como uma nova tendência, jovens das cidades começaram a ocupar as escolas populares em grande número, salvando muitas delas, em crise por causa da migração rural.

17 A exceção à regra foi a Escola de Borup, criada em Copenhague em 1891, que funcionava em período noturno; na década de 1920 inovou com aulas diurnas e integrou-se à vida cultural da cidade, promovendo concertos e tertúlias públicas. 
Por causa do movimento juvenil, as escolas populares abandonaram sua "torre de marfim" e se transformaram em um laboratório social antiautoritarismo [..]. Não há nada de novo em haver críticas sociais vindas dos professores, o que se tornou novo foram as práticas nas escolas (KORSGAARD, 2019, p. 60).

Ao redor de 1990, o número de escolas populares girava em torno de 100. Mas a partir de 1994, esse número começou a cair, reduzindo-se em 30\% em 10 anos. A Ministra da Educação da Dinamarca então criou um comitê para estudar as causas e a partir das suas recomendações um novo ato foi estabelecido em 2006. A partir daí ocorreu um novo crescimento da procura, chegando em 2019, ano em que se comemorou 175 anos da abertura da primeira Folke Hojskoler, ao número de 100 escolas, segundo a Associação Dinamarquesa das Folk High Schools ${ }^{18}$.

\section{Paralelos entre Grundtvig e Freire}

Diversos autores encontraram convergências entre as ideias pedagógicas de Grundtvig e as de outros pensadores influentes no campo educacional do séc. XX, como John Dewey, Jerome Bruner e Paulo Freire (BHATTACHARYA, 2010; KORSGAARD, 2011).

Com efeito, e apesar da distância que afasta no tempo Grundtvig e Freire, das diferenças de formação intelectual entre eles e de contextos históricoculturais em que viveram, encontramos não só afinidades decorrentes do humanismo cristão em que se enraízam as filosofias da educação de ambos, mas também similitudes em conceitos-chave expressos em seus escritos, tais como a crítica implacável à escola tradicional, que o primeiro denominou escolas da morte, e o segundo acusou de promover uma educação bancária (FREIRE, 1987). Os dois autores atribuem à educação um sentido emancipatório (implícito nas respectivas noções de esclarecimento e conscientização), apostam na horizontalidade do vínculo pedagógico entre educador e educandos, e concedem

18 Disponível em: https://www.danishfolkhighschools.com. Para uma visão mais aprofundada do funcionamento contemporâneo das escolas populares na Dinamarca, consultar os estudos de caso realizados Gato (2011), Milana e Sorensen e por Haddad e assistentes, ambos publicados em Haddad (2020). 
centralidade à interação, ao diálogo e à participação no processo educativo como estratégias de construção da autonomia intelectual e de formação para a cidadania democrática. Ambos autores colocaram a cultura popular no centro dos processos formativos, contudo os conceitos de "povo" e "popular" de um e outro diferiam significativamente, por força dos contextos histórico-nacionais em que desenvolveram as respectivas filosofias da educação. A concepção de democracia de Grundtvig colocava ênfase na dimensão cultural, à medida que compreendia o povo como um agregado linguístico e cultural, e a nação como um conjunto de pessoas partilhando a mesma língua, história e tradição; já para Freire a concepção de democracia é essencialmente política, envolvendo a busca de superação de relações de dominação, exploração e alienação, perspectiva mais próxima àquela de Hal Koch, que renovou o ideal grundtviguiano no pós-guerras.

\section{Remate}

Se o campo da educação popular contemporânea é plural, configurando um pensamento vivo em movimento e disputa, como interpretou Jara (2020, p. 197), também não se nutre de uma única fonte; múltiplos afluentes concorrem para essa vertente de teorização sobre a formação das pessoas jovens e adultas. Dentre seus precursores na América Latina, os historiadores reconhecem na transição dos séculos XIX ao XX lideranças políticas associadas às correntes nacional-popular, anarco-sindicalista e socialista (PUIGGRÓS, 1998), ao passo que o recente giro decolonial reivindica a incorporação das cosmovisões dos povos originários e da diáspora africana (JARA, 2020). Da Europa, a literatura sobre a educação com adultos recupera o pioneirismo das instituições de livre ensino e as pedagogias libertárias dos anarquistas espanhóis (SILVA, 2011), assim como o pensamento e atuação de historiadores marxistas ingleses junto aos sindicatos de trabalhadores (VENDRAMINI; TIRIBA, 2014). Nossa pesquisa sugere que as práticas e o pensamento da educação popular contemporâneos são tributários também da filosofia da educação de Nikolaj Frederik Severin Grundtvig e de sua concretização nas escolas populares da Escandinávia, que enriquecem e aprofundam a teoria pedagógica do campo. 


\section{REFERÊNCIAS}

ABRAMOVAY, Ricardo. Paradigmas do Capitalismo Agrário em Questão. 3. ed. São Paulo: EDUSP, 2007.

BAACK, Lawrence. J. Agrarian Reform in Eighteenth-Century Denmark. Lincoln, Nebraska: University of Nebraska Studies, 1977.

BHATTACHARYA, Asoke. Education for the People: Concepts of Grundtvig, Tagore, Gandhi and Freire. Rotterdam: Sense Publishing, 2010.

BJERG, Jens. Christen Mikkelsen Kold (1816-70). Prospects, Paris, Unesco, v. 24, n. 1-2, p. 21-35, 1994.

BROADBRIDGE, Edward; WARREN, Clay; JONAS, Uffe (ed.). The School for Life: N.F.S. Grundtvig on Education for the People. Dinamarca: Aarhus University Press, 2011.

FREIRE, Paulo. Pedagogia do Oprimido. 20. ed. São Paulo: Paz e Terra, 1987.

FREIRE, Paulo; HORTON, Myles. O caminho se faz caminhando: conversas sobre educação e mudança social. Petrópolis: Vozes, 2011.

GADOTTI, Moacir et al. (org.). Paulo Freire: uma biobibliografia. São Paulo: Cortez, IPF, 1996.

GATO, Rui Pedro Madeira. N F S Grundtvig e as escolas populares dinamarquesas: contributos para a educação de adultos. 2011. 202 f. Dissertação (Mestrado em Ciências da Educação) - Universidade de Lisboa, Lisboa, 2011. Disponível em https://repositorio. ul.pt/handle/10451/6310. Acesso em: 19 out. 2021.

HADDAD, Sérgio et al. Grundtvig e as Folk High Schools, a experiência dinamarquesa em Educação de Jovens e Adultos. In: HADDAD, Sérgio (org.). Grundtvig e Freire: escolas populares na Dinamarca e no Brasil. São Paulo: Ação Educativa, 2020. p. 129-156.

JARA, Oscar. Educação popular latino-americana: história e fundamentos éticos, políticos e pedagógicos. São Paulo: Ação Educativa: CEAAL: Enfoc, 2020.

JENSEN, Niels Lyhne (ed.). A Grundtvig Anthology: Selections from the writings of N. F. S. Grundtvig (1783-1872). Cambridge: James Clarke \& Co, 1984.

KNUDSEN, Johannes (ed.). N. F. S. Grundtvig: Selected Writings. Philadelphia: Fortress Press, 1976.

KORSGAARD, Ove. Grundtvig's philosophy of enlightenment and education. In: BROADBRIDGE, Edward; WARREN, Clay; JONAS, Uffe (ed.). The School for Life: N.F.S. Dinamarca: Aarhus University Press, 2011.

KORSGAARD, Ove. A foray into Folk High School ideology. Dinamarca: FFDs Forlag, 2019. 
LAWSON, Max (comp.). N. F. S. Grundtvig Selected Educational Writings. Skive, Dinamarca: The Association of Folk High Schools in Denmark, 1991.

LEMME, Paschoal. Educação supletiva - educação de adultos. In: BRANDÃO, Zaia. Paschoal Lemme. Recife: Fundação Joaquim Nabuco: Massangana, 2010. p. 121-129. (Coleção Educadores).

MILANA, Marcella; SORENSEN, Tore Bernt. Promoção da Cidadania Democrática através da Educação de Adultos Não-Formal: O caso da Dinamarca. In: HADDAD, Sérgio (org.) Grundtvig e Freire: escolas populares na Dinamarca e no Brasil. São Paulo: Ação Educativa, 2020. p. 106-128.

PUIGGRÓS, Adriana. La educación popular en América Latina: orígenes, polémicas y perspectivas. Buenos Ayres: Miño y Dávila, 1998.

SILVA, Doris Accioly e. Anarquistas: criação cultural, invenção pedagógica. Educ. Soc., Campinas, v. 32, n. 114, p. 87-102, 2011. Disponível em: https://doi.org/10.1590/ S0101-73302011000100006. Acesso em: 20 out. 2021.

VENDRAMINI, Celia Regina; TIRIBA, Lia. Classe, cultura e experiência na obra de E. P. Thompson: contribuições para a pesquisa em educação. Revista HISTEDBR Online, Campinas, n. 55, p. 54-72, mar. 2014. Disponível em: https://doi.org/10.20396/rho. v14i55.8640461. Acesso em: 20 out. 2021.

WARREN, Clay. The International Reception of N.F.S. Grundtvig's Educational Ideas. In: BROADBRIDGE, Edward; WARREN, Clay; JONAS, Uffe (ed.). The School for Life: N.F.S. Grundtvig on Education for the People. Dinamarca: Aarhus University Press, 2011, p. 352-369.

Texto recebido em 10/10/2021.

Texto aprovado em 28/10/2021. 